\title{
GRUPO BONAPARTE: APRENDENDO COM UMA CADEIA DE RESTAURANTES DO NORDESTE BRASILEIRO
}

\author{
THE BONAPARTE GROUP: LEARNING FROM A CHAIN OF \\ ESTAURANTS IN BRAZIL'S NORTHEAST
}

Recebido em: 07/06/2013 Aprovado em: 22/07/2013
Avaliado pelo sistema double blind review
Editora Científica: Manolita Correia Lima

\begin{abstract}
VIVIANESANTOSSALAZAR viviane_salazar@yahoo.com.br WALTER FERNANDO ARAÚJO DE MORAES

UNIVERSIDADE FEDERAL DE PERNAMBUCO
\end{abstract}

\author{
YÁKARA VASCONCELOS PEREIRA LEITE \\ UNIVERSIDADE FEDERAL RURAL DO SEMI-ÁRIDO
}

\begin{abstract}
RESUMO
Este caso de ensino visa mostrar os desafios enfrentados por uma empresa de food service, o Grupo Bonaparte, no processo de expansão internacional. A corporação está ampliando as suas atividades para um mercado mais competitivo que é o norte-americano, com isso, vem passando por novas e difíceis situações. Alguns questionamentos permeiam as ações da empresa, a saber: Por que a corporação escolheu os Estados Unidos que é o berço do fast food, pioneiro no setor de franquias e muito mais competitivo do que o brasileiro? Quais as vantagens de entrar nesse mercado? O caso pode ser utilizado nas turmas de graduação, posterior ou concomitante aos conceitos básicos de Administração Estratégica de Internacionalização de Empresas e de Marketing. Recomenda-se o uso especialmente em sessões que estratégias internacionais, marketing de serviços, estratégias de crescimento, vantagem competitiva e empreendedorismo estejam sendo discutidos.

Palavras-chave: caso de ensino; estratégias de internacionalização; restaurantes.
\end{abstract}

\section{ABSTRACT}

This teaching case aims to demonstrate the challenges faced by a food service company, in this case, the Bonaparte Group, undergoing a process of international expansion. The corporation is expanding its activities to a more competitive market, the US, and so faces new and difficult situations. Certain issues are central to the company's actions: why choose the US - the birthplace of fast food and global leader in the franchise industry, which is also much more competitive than Brazil. What are the advantages of entering this market? The case is intended for use at the undergraduate level, after or at the same time as basic strategic internationalization in business administration or marketing courses. It is especially recommended for sessions in which international strategies, marketing services, growth strategies, competitive advantage and entrepreneurship are being discussed.

Keywords: teaching case; internationalization strategies; restaurants. 


\section{INTRODUÇÃO}

Baseado no desenvolvimento tecnológico nos sistemas de transporte e de comunicação tem sido possível às nações intensificar suas relações econômicas, ampliando o acesso a insumos e a mercados com resultados crescentes na internacionalização das empresas que pode ser conceituada como um processo crescente e continuado de envolvimento de uma empresa nas operações com outros países fora de sua base de origem.

A internacionalização antes muito mais restrita aos produtos manufaturados está aumentando também no setor terciário dos serviços graças, principalmente, a economia da informação facilitada pela difusão da microeletrônica.

No mercado global, a participação dos serviços na economia tem aumentado consideravelmente e diversos tipos de serviços respondem por $30 \%$ do comércio mundial. Este crescimento não está restrito aos países desenvolvidos. Nações em desenvolvimento como China e Indonésia empregam quase $40 \%$ da sua força de trabalho no setor de serviços. Dentre os fatores que têm contribuído para a internacionalização deste setor destacam-se a criação da Organização Mundial do Comércio (OMC) e o estabelecimento dos blocos econômicos regionais como a NAFTA (North America Free Trade Agreement) e a União Europeia; os avanços tecnológicos em informação e telecomunicações e a diferenciação dos produtos por meio da incorporação de serviços (KON, 1999).

Dentre os serviços, a indústria da alimentação fora do lar tem se consolidado como uma das principais atividades econômicas de vários países. No Brasil, segundo dados do IBGE/ABIA, em 1998 a porcentagem gasta com alimentação fora do lar era de $22,5 \%$, em 2009 já representava $28,9 \%$, e em 2010 representou $31 \%$. Esse percentual é inferior ao verificado nos Estados Unidos, porém, é maior do que a média nos 27 países que compõem a União Europeia (ABIA, 20IO). Apesar da crise econômica e financeira que reverteu à tendência de crescimento da participação da alimentação fora do lar, nos EUA o percentual do consumo fora do lar chegou a $51 \%$ em 2006 e recuou para os atuais $42 \%$. O cenário gastronômico brasileiro tem 
se modificado bastante graças principalmente à efervescência econômica dos últimos anos. Segundo a Revista Exame (20II), desde 2004 o número de restaurantes e lanchonetes cresceu $9 \%$ e os estabelecimentos tiveram um aumento no movimento, $87 \%$ mais do que há cinco anos.

Em 20I0, o mercado de food service movimentou cerca de R\$ I80 bilhões e para os próximos dez anos estima-se que os brasileiros passarão a fazer não só uma, mas duas alimentações fora do lar, o que fará com que o número de refeições fora de casa salte de 57 milhões para 80 milhões por dia. $\mathrm{O}$ número de restaurantes no Brasil passou de 320.000 em 2004 para $350.000 \mathrm{em}$ 2008. Um dos fatores que podem explicar esse crescimento está na crescente integração das mulheres ao mercado de trabalho. Em menos de três décadas, o número de mulheres economicamente ativas quase dobrou. Segundo dados do IBGE, no ano de 197I a participação das mulheres na População Economicamente Ativa era de $23 \%$, aumentando para 43,6\% em 2008, e a expectativa é que em 20I2, $46 \%$ da população de trabalhadores brasileiros seja do sexo feminino (IBGE, 20IO).

Outro ponto importante a ser analisado é o aumento da distância em quilômetros, e tempo gasto, especialmente nas grandes metrópoles, entre o local de trabalho e a residência, indicando que as pessoas não têm mais tempo para fazer suas refeições em casa. Ainda segundo este estudo, as regiões Norte e Nordeste apresentam os menores percentuais, sendo que pouco mais de $20 \%$ das despesas familiares com alimentação são realizadas fora do lar. Com base nesses dados, este caso de ensino visa mostrar os desafios enfrentados por uma empresa totalmente nordestina de food service, o Grupo Bonaparte, no processo de expansão internacional. A corporação está ampliando as suas atividades para um mercado muito mais competitivo que é o norte-americano, com isso, vem passando por novas e difíceis situações. Então, por que a corporação escolheu os Estados Unidos que é o berço do fast food, pioneiro no setor de franquias e um mercado muito mais competitivo do que o brasileiro? Quais as vantagens que o Grupo Bonaparte pode conseguir no mercado americano?

Devido a sua importância regional e nacional, o processo de internacionalização do Grupo Bonaparte é um caso interessante para 
se estudar. Desse modo, o leitor se posicionará como os atuais gestores da empresa para refletir sobre quais ações da administração estratégica deverão implantar com o objetivo de manter a cadeia de restaurantes em atividade também nos mercados estrangeiros. 


\section{O GRUPO BONAPARTE}

O grupo Bonaparte surgiu em 1996, da parceria entre os empresários Leonardo Lamartine e Roberto Bitu, respectivamente sócios diretores e responsáveis pela administração do grupo. Atualmente é líder de vendas por metro quadrado nos shoppings em que atua no Nordeste, além de se encontrar na $28^{\mathrm{a}}$ posição entre as Ioo franquias mais lucrativas em atividade no Brasil, inclusive considerando as multinacionais, segundo a Associação Brasileira de Franchising, em uma pesquisa feita em 2009. Hoje, o grupo possui mais de 56 lojas espalhadas em I3 estados da federação, mais especificamente nas regiões Nordeste e Centro Oeste. Seu principal produto são refeições, a maioria é servida no horário do almoço nas praças de alimentação dos shoppings centers. O volume de vendas mensal é de aproximadamente 5.500 pratos/loja. Em 2009, o grupo Bonaparte apresentou um faturamento I5\% superior ao de 2008 . O bom momento da marca se reflete, ainda, no primeiro trimestre de 20Io, período em que apresentou um crescimento de $8 \%$ em relação ao ano anterior. Levado pelo desenvolvimento da economia de Pernambuco, que graças a investimentos estruturantes como o Estaleiro Atlântico Sul e investimentos no Porto de Suape tem apresentado um crescimento de $7 \%$ ao ano, superior a maioria dos Estados do país. Além disso, o grupo planeja mais uma expansão para o interior pernambucano e para o Sudeste do país.

Como prova da ousadia e empreendedorismo dos seus diretores, o Grupo Bonaparte foi a primeira empresa brasileira, no segmento fast food, a inverter a regra migratória das franquias, que invariavelmente indicava um fluxo do Sudeste para o Nordeste, inaugurando, em 2002 - sete anos depois de sua criação - a primeira franquia Bonaparte no Rio de Janeiro. O Grupo possui em média sessenta funcionários diretos trabalhando em seu escritório e I.500 trabalhando em alguma de suas franquias.

Atualmente, a corporação possui cinco marcas: (i) o Bonaparte; (ii) o Donatário; (iii) o Monalisa; (iv) o Galileu; e (v) o Bossa Grill - inaugurado em julho de 2oro, sendo este último localizado na cidade de Wichita, Estado do Kansas, nos Estado Unidos da América. 
O Bonaparte foi a primeira marca do grupo e surgiu em 1998 após um cuidadoso estudo mercadológico que detectou alguns anseios de clientes habituais de fast food que ainda não haviam sido satisfatoriamente respondidos. O Bonaparte encontrou o seu trunfo na racionalização do cardápio e na otimização do espaço físico reduzido, comum a grande parte dos restaurantes localizados dentro de shopping centers. A composição do cardápio e a agilidade do atendimento, no entanto, são inversamente proporcionais à área que o restaurante ocupa. O cardápio tem como base cortes de ave, carne, peixe e oferece até I5 opções de acompanhamento, com inúmeras possibilidades de combinação entre si. O Bonaparte revolucionou o conceito geralmente atribuído a refeições rápidas, que fixou a ideia de uma alimentação pobre em sabor e aparência. Utilizando ingredientes nobres, carnes de primeira e absoluto rigor e padronização na preparação dos pratos, o Bonaparte tem se firmado como uma opção gastronômica de alto nível, sem que seja necessário sacrificar a agilidade exigida por sua característica de fast food.

Na rede Donatário, o camarão é o carro-chefe, embora o cardápio também contemple receitas de filé, peixe, salmão, risotos, saladas e massas. Fornecidos por grandes fazendas de carcinicultura do país, com tamanho maior, os camarões utilizados nos pratos do Donatário são précozidos, sem casca, preparados na hora, a pedido do cliente, garantindo assim, a preservação de textura e sabor.

O Galileu é uma reformulação do antigo Galetasso e originalmente objetivava ser uma opção requintada para quem escolhia pratos a base de frango como refeição principal. No entanto, a nova linha de comunicação visa estabelecer um conceito de culinária contemporânea, que oferece opções distintas de pratos, misturando sabores e ingredientes como demanda a cozinha moderna. Nessa marca, são oferecidos pescados, carnes, aves e saladas em pratos requintados, sofisticados e novos, como diz o slogan adotado "Reinventando o sabor".

O Monalisa surgiu baseado na ideia de apostar na cozinha italiana, após três bem sucedidas experiências do Grupo Bonaparte. O tema 
Itália também foi usado na concepção de sua marca e no layout dos restaurantes. A identidade visual do empreendimento utilizou elementos dessa cultura.

Por fim, a última marca a ser lançada e objeto de análise deste estudo foi o Bossa Grill. Esse produto foi todo concebido para dar início ao processo de internacionalização do Grupo Bonaparte conforme será tratado a seguir. 


\section{O PROCESSO DE INTERNACIONALIZAÇÃO}

A efetiva abertura de uma operação nos EUA aconteceu apenas em julho de 2010 apesar do processo ter iniciado em 2008. Os empreendedores do Grupo Bonaparte já pensavam em internacionalizar a empresa e estavam fazendo prospecções de mercado nos EUA. Em 2008, o grupo foi procurado por um administrador financeiro que já havia trabalhado por muitos anos no Grupo pernambucano RENDA, Sr. Alberto Moreira, e cujo filho trabalhava e residia nos Estados Unidos, especificamente na cidade de Wichita, Estado do Kansas. Este estava interessado em montar um restaurante com apelo à cultura brasileira nesta cidade que é a maior do Estado do Kansas. Nela estão localizadas todas as empresas de aviação particular e por isso tem um fluxo de turista de negócio muito grande. A escolha pelo Grupo se deve à reputação positiva e o pioneirismo no mercado de franquias. O processo teve início em julho de 2008, quando o Sr. Alberto mudou-se para Wichita para dar início às pesquisas de marketing, prospecção de mercado e efetiva abertura da empresa. Porém, em setembro daquele ano, uma grave crise financeira afetou a economia mundial e os planos foram adiados. Na visão dos empreendedores, apesar da crise ter retardado o início das operações devido à alta do dólar e consequente aumento do investimento para o setor de alimentação nos EUA, ela se mostrou favorável para o tipo de produto, o Bossa Grill, que o Grupo Bonaparte formatou como restaurante casual dinner, tratado adiante. Para Luiz, gerente de marketing do grupo:

Não foi uma questão de falta de mercado nos Estados Unidos, muito pelo contrário, o mercado até melhorou com esse segmento de fast casual, pois, caiu o ticket médio e as pessoas deixaram de comer nos restaurantes mais chiques para ir comer nesse modelo de operação [...]. Mas havia um problema do câmbio então, o câmbio oscilando sem a gente saber onde ia parar inviabilizou o investimento naquele momento (informação verbal).

No processo de internacionalização, uma das decisões mais importantes se refere onde "entrar" primeiro. Dentre as explicações dos destinos escolhidos pelas empresas para darem início ao processo de internacionalização destacam-se as vantagens de localização - abundância de recursos 
naturais ou humanos com qualidade e baixo custo, know how tecnológico, infraestrutura, instituições, tamanho do mercado, estabilidade política e econômica, regime cambial e esquema de política econômica - oferecidas por um dado país ou região. O mercado de alimentação fora do lar nos EUA é muito maior do que o brasileiro, a média de gastos das famílias americanas com alimentação gira em torno de $42 \%$, bem acima do gasto dos brasileiros (31\%) e parece ter sido justamente esta a maior razão da escolha do país de destino como afirma o Sr. Luís:

Porque é um mercado muito desenvolvido, a gente tem um lado de consumo super favorável lá. Mais de $40 \%$ do que se ganha de renda nos Estados Unidos se gasta com alimentação fora do lar, então, eles comem muito fora de casa, então, é um mercado pulsante (informação verbal).

Este pensamento é corroborado por Leonardo Lamartine quando afirma que: Então, é um mercado extremamente desenvolvido, porém, muito concorrido. Lá nos Estados Unidos, $42 \%$ da renda do americano é gasta com refeições fora do lar [...] o que chamou atenção foi os números e a estabilidade, vamos dizer assim, para planejamento (informação verbal).

As razões que levaram o grupo a buscar mercados internacionais foram tanto a expansão de mercado como também o perfil empreendedor do seu principal diretor-fundador, Sr. Leonardo Lamartine. A primeira escolha foi em que cidade se instalar e a definição por Wichita no Estado do Kansas não foi fácil. A princípio, os empreendedores ficaram muito receosos principalmente pela cidade ser do interior e ter um clima muito diferente do tropical. Mas devido à rede de relacionamentos do Sr. Alberto e do seu filho Marcelo naquela cidade ser muito extensa optou-se pelo início da operação nela. Ademais, segundo Leonardo, em cidades maiores como Dallas, Chicago ou Nova York a nova marca iria ser fortemente atacada pela concorrência. Porque se o início ocorresse por Miami ou Orlando, a rede poderia sofrer preconceito do restante dos Estados Unidos.

Definido o início do processo, faltava resolver qual seria o produto a ser internacionalizado. A princípio pensou-se em internacionalizar a marca Bonaparte, visto que esta é a mais antiga e mais consolidada marca do grupo. Porém, após várias pesquisas de mercado realizadas em parceria 
com a Universidade do Kansas, percebeu-se certa resistência em relação ao nome Napoleão Bonaparte e a cultura francesa. Em contrapartida, esta mesma pesquisa identificou certa aceitação da cultura brasileira e dentre os cinco nomes que os americanos associavam com a cultura brasileira - Pelé, Bossa Nova, Samba, Amazônia e Rio de Janeiro - escolheu-se trabalhar com a temática da Bossa Nova. O modelo de negócio adotado foi o chamado fast casual. Este modelo de serviço difere dos restaurantes tradicionais porque agrega características do fast food com pratos de qualidade e preços acessíveis.

Assim, o produto foi pensado e desenvolvido considerando esta temática conforme atesta o gerente de marketing:

A gente procurou trabalhar a temática da Bossa Nova em todo o contexto do restaurante então, as cores pretas, brancas e vermelhas foram tiradas do que era usual da Bossa Nova. O calçadão de Copacabana virou marca da Bossa Grill, [...] na loja a gente tem a entrada do restaurante todo do calçadão de Copacabana até o caixa então ele entra mesmo nessa cultura do Rio de Janeiro. Têm quadros em preto e branco mostrando o Rio de Janeiro, o Corcovado, o Pão de Açúcar então ele vai começando a interagir com essa cultura da Bossa Nova. O som é todo Bossa Nova, tocando o dia inteiro dentro do restaurante [...](informação verbal).

Apesar de a temática do restaurante ser Brasil, o Bossa Grill não é mais um restaurante brasileiro nos EUA para um público de brasileiros que moram nos EUA e sentem falta da comida. O cardápio é de comida internacional, porém com toques brasileiros como, por exemplo, o feijão preto e a tentativa de introduzir a farofa de mandioca.

$\mathrm{Na}$ concepção do cardápio houve adaptações para o gosto do americano. O cardápio foi concebido usando um mix dos melhores pratos das quatro marcas brasileiras e adaptados ao paladar americano no que se refere ao sabor - mais picante e adocicado - e gramatura - pois o americano come mais. Sobre esse aspecto Luís relata que:

A gente procurou reunir os melhores pratos dessas marcas e adaptar para o paladar americano. E o nosso foco é vender para americano e não vender para brasileiro e nem para latino. A gente tem um público de brasileiro e latino 
grande pela temática do restaurante, mas a gente procurou pegar o melhor das outras marcas do Brasil adaptar para o paladar americano, trabalhar [...] sabor para que a gente pudesse atingir melhor o público americano (informação verbal).

A adaptação aconteceu também no que se refere não só a legislação trabalhista, mas ao método de trabalho, pois na cultura americana, o trabalho é bastante diferente da brasileira. Se por um lado não há uma carga tributária muito alta atrelada à manutenção de um funcionário, por outro lado não há comprometimento do trabalhador com a empresa conforme atesta Luís:

A gente teve que se ajustar a algumas culturas profissionais, cultura deles mesmo com relação a trabalho, a como lidar com o trabalho, a maneira como as coisas fluem no processo, precisavam estar definidos para que eles tivessem facilidade de operar dentro da loja que é um pouco diferente do que a gente tem aqui no Brasil. Aqui no Brasil a gente contrata um cozinheiro e ele tem lá um livro de receita e ele executa. Mas nos Estados Unidos você precisa dizer a hora que ele começa a fazer isso, a hora que ele começa a fazer aquilo porque ele segue exatamente o que está no livro e o que tiver fora do livro não espere porque ele não vai fazer (informação verbal).

Por fim, uma inovação importante no que se refere ao produto é que no Brasil, todas as marcas operam em praças de alimentação em shoppings centers e nos Estados Unidos o Bossa Grill é uma operação de rua.

$\mathrm{O}$ modo de entrada no mercado norte-americano foi a franquia. Foram montadas nos EUA duas empresas: uma empresa franqueadora máster Bossa Group formada por quatro sócios: o grupo Bonaparte, o grupo Renda, Michael R. Biggs - advogado americano especialista em franquias e Alberto Moreira - sócio minoritário. E esta franqueadora fez o investimento na primeira loja do grupo de aproximadamente US\$500 mil. O planejamento inicial era após seis meses inaugurar outra unidade também com capital próprio no oeste da Wichita, mas no momento, este prazo foi reprogramado. Apesar disso, o Bossa Group tem metas bastante ousadas, visto que o projeto é que em Io anos de operação nos EUA o número de operações seja o dobro das operações no Brasil, ou seja, em mais ou menos Ioo restaurantes abertos. 
Isto graças à dinâmica do mercado que é bastante diferente nos dois países. Enquanto que no Brasil cada franqueado tem poucas lojas, nos EUA quando uma franquia decide expandir "[...] encontra os fundos de investimentos privados, e montam quarenta ou cinquenta lojas numa tacada só, diferente do que acontece aqui no Brasil”, conforme afirma Leonardo.

É interessante também destacar a rede de relacionamentos do principal executivo do Grupo Bonaparte e o seu papel neste processo de internacionalização. Durante quatro anos, Leonardo Lamartine foi também Presidente da ABRASEL - Associação Brasileira de Bares e Restaurantes, seccional Pernambuco. E neste tempo fez várias viagens aos Estados Unidos para participar da NRA (National Restaurant Association), maior feira de alimentação do país, e nesta feira fez vários contatos com fornecedores o que facilitou o início das operações nos EuA, visto que a rede cobre basicamente todo o território americano, conforme atesta Leonardo:

Acho que o fato de eu ter sido presidente da ABRASEL foi que me trouxe o contato que eu tenho com o consulado americano [...] o fato de eu ser muito organizado em relação ao meu network, no sentido, de eu sempre anotar os contatos que eu faço, quais são as empresas e tal, independente de eu nem imaginar que ia para os Estados Unidos, mas isso me ajudou também na busca de fornecedores, os contatos, por exemplo, do pessoal da Micros que é uma empresa de sistema de informática, que atende a gente em Wichita, foram feitos nessas feiras da NRA [...](informação verbal).

Também graças a essas viagens e a este papel desempenhado, Leonardo conheceu o Michael Biggs, um dos maiores advogados especialistas em franquias dos EuA, que se tornou sócio da empresa franqueadora e tem o papel de desenvolver essa rede de relacionamento para a continuidade da expansão.

Quanto ao futuro da internacionalização do Grupo, o plano é consolidar a marca nos Estados Unidos e expandir para Estados como Flórida e Texas. Para isso, a empresa procura brasileiros com perfil empreendedor que queiram imigrar para os Estados Unidos conforme atesta Leonardo:

Está dentro da nossa estratégia de expansão, pessoas que querem migrar para os Estados Unidos, que tem um perfil de empreendedor, que tem um perfil 
de investimento [...] e aí nosso escritório de advocacia que já nos atende vão dar todo o suporte para fazer uma migração legal e isso é muito comum nos Estados Unidos (informação verbal).

Fora dos Estados Unidos, o grupo iniciou conversas com empresários Angolanos e as negociações estão bastante avançadas. E quanto a Portugal, onde as conversas são iniciais, em ambas as operações a marca usada será a Bonaparte. 


\section{POSSÍVEIS OBSTÁCULOS}

Para continuar o processo de internacionalização, os desafios que se apresentam ao Grupo Bonaparte são muitos. Os gestores não sabem ao certo quando e onde será inaugurado o próximo restaurante da rede. Existem de 6 a 8 candidaturas de investidores de Miami para a marca Bossa. Enquanto que em Portugal e na Angola, pretende-se implantar a Bonaparte. Todavia, deve-se questionar: será que a marca Bonaparte é a mais adequada para Portugal e Angola? Além disso, problemas econômicos no caso de Portugal e sociopolíticos na Angola precisam ser analisados antes de efetivar um contrato de franquia.

A legislação também é um aspecto relevante no processo de internacionalização de serviços. Houve muitas adaptações que precisaram ser feitas como o número de funcionários de loja. Pela própria legislação trabalhista nos EUA, para operar uma loja são necessários mais funcionários, pois muitos simplesmente param de trabalhar quando querem, como explica o Sr. Luís:

[...] não esperava que eu precisasse de tantos funcionários pra preencher um schedule curto, o que acontece, eu posso ter 40 funcionários, selecionar tantos para aquele horário e tanto faz ele vir ou ele não vir, porque se ele tiver nesse horário em outro lugar, ele também não avisa, ele simplesmente não vem, então é questão de um comprometimento profissional com a empresa, a gente sentiu um certo choque no início. Aí depois a gente percebeu que realmente precisamos ter um leque grande, porque na hora que um não vem o outro vem, a gente chama de última hora e vai preenchendo as lacunas (informação verbal).

Além desse cuidado com a escala de trabalho, a organização precisou se posicionar perante os funcionários de um modo que não fosse processada. Diferentemente do que acontece no Brasil, o gestor que atua no território americano não pode nem perguntar ao subordinado qual a sua religião ou se fuma. Outro aspecto tem relação com descrição do trabalho, é preciso apresentar todo o procedimento minuciosamente, do contrário, as atividades não serão realizadas pelos funcionários. Esse tipo de adaptação seria um 
tipo de responsividade operacional, existente na internacionalização de serviços?

Quanto à concorrência, com o ticket médio em torno de Io a I2 dólares por pessoa, ainda é cedo para dizer se o produto Bossa obteve sucesso, porém, mesmo com esse grande mercado, será que a escolha da localização foi acertada? O Sr. Luís faz comentários sobre o assunto:

Meus concorrentes nos Estados Unidos seriam basicamente Pei Wei, que é uma operação de lá, é uma operação fast casual de um à la carte lá [...], comida chinesa oriental, acho que o Pei Wei e um pouco o Chipotle que é uma operação aqui, que não sei se pertencia ao McDonalds (informação verbal).

Diferentemente do Pei Wei e do Chipotle, o Bossa não é uma marca conhecida e nem tampouco está com pretensão de se expandir para outros países além dos EuA. Não seria este mais um ponto fraco da marca? Talvez uma opção fosse tratar a comunicação de marketing de forma integrada com o apelo multimarcas, passando a apresentar o Bonaparte, Monalisa, Donatário, Galileu e Bossa como pertencentes ao mesmo grupo. Isso talvez facilitasse a internacionalização do Grupo. 


\section{NOTAS DE ENSINO}

\section{OBJETIVOS EDUCACIONAIS}

- Fazer com que os alunos avaliem e discutam o processo de internacionalização de um restaurante, as principais estratégias adotadas, considerando o seu conteúdo, contexto e processo (PETTIGREW, 20I2);

- Relacionar o embasamento teórico às atividades desenvolvidas pela organização em foco, e fazer com que os alunos sejam capazes de discernir e tomar decisões estratégicas sobre o processo de internacionalização de uma empresa (ANDERSSON, 2000; BUTLER; DOKTOR; LINS, 2OIO; CARNEIRO; DIB, 2007; DUNNING, I988, I989; EDVARDSSON; EDVINSSON; NYSTRÖM, I993; ERRAMILLI, I990; ERRAMILLI; RAO, I990; ERRAMILLI, I993; FARHI ET AL., 2009; FERREIRA ET AL., 2009; FORD, 2002; HILAL; HEMAIS, 2003; JAVALGI; MARTIN, 2007; JOHANSON; VAHLNE, I977, 2009; KNIGHT, I999; KON, I999; KOVACS, 2009; LEITE; MORAES, 20I3; LOVELOCK; YIP, I996; VERNON, I966; ZEITHAML; BITNER, 2003).

\section{UTILIZAÇÃO RECOMENDADA}

O caso pode ser utilizado nas turmas de graduação, posterior ou concomitante aos conceitos básicos de Administração Estratégica de Internacionalização de Empresas, Marketing Estratégico, Empreendedorismo e Gestão de Pessoas. Recomenda-se o uso, especialmente em sessões que estratégias internacionais, marketing de serviços, estratégias de crescimento, vantagem competitiva, gestão de pessoas e empreendedorismo estejam sendo discutidos. Em Gestão de Pessoas, o destaque se dá nos aspectos culturais do trabalhador nativo em comparação com a cultura brasileira, bem como dos expatriados, ao mencionar a estratégia da empresa em buscar brasileiros para serem franqueados nos Estados Unidos.

\section{FONTE DE OBTENÇÃO DE DADOS}

Os dados que fundamentaram este trabalho foram coletados em fontes bibliográficas e em entrevistas realizadas com o gerente de marketing do 
Grupo Bonaparte e o diretor executivo Leonardo Lamartine durante o período de novembro e dezembro de 2oro. Ademais, informações do site do próprio grupo, da revista Exame, dos livros e de artigos acadêmicos foram coletadas até 2013 .

\section{QUESTÕES PARA DISCUSSÃO}

Algumas questões são apresentadas para apoiar a discussão do caso:

1 Como você descreve o ambiente de negócios do Grupo Bonaparte? Quais as principais oportunidades e ameaças do ambiente?

2 Descreva o ambiente interno da marca Bossa, identificando as suas forças e fraquezas.

3 Qual foi o modo de entrada escolhido pelo Grupo Bonaparte para se internacionalizar? Quais motivos levaram a essa escolha?

4 A distância psíquica foi determinante no processo de internacionalização? Por quê?

5 Por que a escolha dos EUA, considerando que é um mercado muito mais competitivo do que o brasileiro?

6 Quais foram as ações de responsividade na concepção do produto Bossa Grill? Elas foram necessárias? Por quê?

7 Para se internacionalizar, o Grupo Bonaparte fez ajustes na sua operação, diretamente relacionados às pessoas. Quais são as consequências dessa ação?

8 Quais são os desafios da gestão de pessoas para implantar as estratégias empresariais?

9 Como os gestores devem tratar a concorrência americana?

10 A cadeia de restaurantes possui alguma vantagem competitiva? Por quê?

11 Qual foi o papel das redes de relacionamentos para a internacionalização?

12 Como o empreendedor influenciou as estratégias ao longo da trajetória do Grupo Bonaparte?

13 Como dimensões do empreendedorismo, oportunidades e inovação, foram trabalhadas pelos dirigentes?

14 Quais as vantagens que o Grupo Bonaparte pode conseguir no mercado americano? 
15 No lugar dos dirigentes, qual seria o seu plano e ações para continuar o processo de internacionalização?

Finalmente, o professor retoma o objetivo da discussão, sintetiza as principais ideias, confere se as temáticas foram cobertas e faz ligação com os assuntos já discutidos em sala de aula e os que serão apresentados nos próximos encontros. 


\section{REFERÊNCIAS}

ABIA. Disponível em: <http//:www.abia.org.br>. Acesso em: 16/09/2010.

ANDERSSON, S. The Internationalization of the firm from an entrepreneurial perspective. International Studies of Management \& Organization, v. 30, n. 1, p. 63-92, 2000.

BUTLER, J. E.; DOKTOR, R.; LINS, F. A. Linking international entrepreneurship to uncertainty, opportunity discovery, and cognition. Journal of International Entrepreneurship, v. 8, n. 2, p. 121-134, 2010.

CARNEIRO, J.; DIB, L. A. Avaliação comparativa do escopo descritivo e explanatório dos principais modelos de internacionalização de empresas. INTERNEXT-Revista Eletrônica de Negócios Internacionais da ESPM, v.2, n.1, p. 1-25, 2007.

DUNNING, J. H. The eclectic paradigm of international production: a restatement and some possible extensions. Journal of International Business Studies, v. 19, n. 1, p. 1-31, 1988.

DUNNING, J. H. Multinational enterprises and the growth of services: some conceptual and theoretical issues. The Service Industries Journal, v. 9, n. 1, p. 5-39, 1989. EDVARDSSON, B.; EDVINSSON, L.; NYSTRÖM, H. Internationalization in service companies. The Service Industries Journal, v. 13, n. 1, p. 80-97, 1993.

ERRAMILLI, M. K. Entry mode choice in service industries. International Marketing Review, v. 7, n. 5, p. 50-62, 1990.

ERRAMILLI, M. K; RAO, C. P. Choice of foreign marketing entry modes by service firms: role of marketing knowledge. Management International Review, v. 30, n. 2, p. 139$150,1990$.

ERRAMILLI, M. K; RAO, C. P. Service firm's international entry-mode choice: a modified transaction-cost analysis approach. Journal of Marketing, v. 57, n. 3, p. 19-38, 1993.

EXAME. Edição 984, ano 45, n.1, 26/01/2011.

FARHI, M.; PRATES, D.M.; FREITAS, M.C.P. de; CINTRA, M.A.M. A crise e os desafios para a nova arquitetura financeira internacional. Revista de Economia Política, v. 29, n. 1, p. 135-138, 2009.

FERREIRA, L. F. F.; CAPRA, L.P.; PEREIRA, L.S.; ABREU, M.A.S.S.; SILVEIRA, F.A. Desde os Primórdios até hoje em dia: Será que o Empreendedor ainda faz o que Schumpeter dizia? Evolução das Características Empreendedoras de 1983 a 2010. In: EnAnpad, 35., 2011. Rio de Janeiro. Anais... Rio de Janeiro: Anpad, 2011.

FORD, D. Distribution, internationalization and networks: solving old problems, learning new things and forgetting most of them. International Marketing Review, v. 19, n. 3, p. 225-235, 2002.

GRUPO BONAPARTE. Disponível em: < http://www.grupobonaparte.com.br/>. Acesso 
em: $12 / 04 / 2013$.

HILAL, A.; HEMAIS, C. A. O Processo de Internacionalização na Ótica da Escola Nórdica: Evidências Empíricas em Empresas Brasileiras. Revista de Administração Contemporânea, v. 7, n. 1, p. 109-124, 2003.

IBGE. Disponível em: < http://www.ibge.gov.br/home/estatistica/indicadores/ trabalhoerendimento/pme mulher/Suplemento Mulher 2008.pdf $>$. Acesso em: 15/09/2010.

JAVALGI, R. G.; MARTIN, C. L. Internationalization of services: indentifying the building-blocks for future research. Journal of Services Marketing, v. 21, n. 6, p. 391-397, 2007.

JOHANSON, J.; VAHLNE, J.-E. The internationalization process of the firm - a model of knowledge development and increasing foreign markets commitments. Journal of International Business Studies, v. 8, n. 1, p. 23-32, 1977.

JOHANSON, J.; VAHLNE, J.E. The Uppsala Internationalization Process Model Revisited: from liability of foreignness to liability of outsidership. Journal of International Business Studies, v. 40, n. 9, p. 1411-1431, 2009.

KNIGHT, G. International services marketing: review of research: 1980-1988. Journal of Services Marketing, v. 13, n. 4/5, p. 347-360, 1999.

KON, A. A internacionalização dos serviços. Revista de Administração de Empresas, v. 39, n. 1, p. 42-54, 1999.

KOVACS, E. P. O processo de internacionalização de empresas do Nordeste: proposição de um framework. 2009. 394f. Tese (Doutorado em Administração). Universidade Federal de Pernambuco, Recife, 2009.

LEITE, Y. V. P.; MORAES, W. F. A. de. Propriedades da atitude face ao risco no empreendedorismo internacional. In: 3Es, 6., 2013. Bento Gonçalves/RS. Anais... Bento Gonçalves/RS: Anpad, 2013.

LOVELOCK, C. H.; YIP, G. S. Developing global strategies for service businesses. California Management Review, v. 38, n. 2, p. 64-86, 1996.

PETTIGREW, A. M. Context and action in the transformation of the firm: a reprise. Journal of Management Studies, v.49, n. 7, p. 1304-1328, 2012.

VERNON, R. International investment and international trade in the product cycle. Quarterly Journal of Economics, v. 80, n. 2, p. 191-207, 1966.

ZEITHAML, V.; BITNER, M. J. Marketing de Serviços: a empresa com foco no cliente. 3.ed. São Paulo: Bookman, 2003. 


\section{DADOS DOS AUTORES}

VIVIANE SANTOS SALAZAR viviane_salazar@yahoo.com.br Mestre em Administração pela UFPE

Instituição de vinculação: Universidade Federal de Pernambuco

Recife/PE - Brasil

Áreas de interesse em pesquisa: Estratégia Empresarial, Marketing de Serviços e Hospitalidade.

${ }^{\star}$ Rua Real da Torre 1433, ap.302B Torre Recife/PE 50710-100

WALTER FERNANDO ARAÚJO DE MORAES walter.moraes@ufoe.br PhD em Administração pela UMIST

Instituição de vinculação: Universidade Federal de Pernambuco

Recife/PE - Brasil

Áreas de interesse em pesquisa: Estratégia Empresarial; Internacionalização e Desempenho Empresarial.

YÁKARA VASCONCELOS PEREIRA LEITE yakarav@gmail.com Doutora em Administração pela UFPE

Instituição de vinculação: Universidade Federal Rural do Semi-Árido Mossoró/RN - Brasil

Áreas de interesse em pesquisa: Administração estratégica, Marketing, Ensino e Pesquisa em Administração e internacionalização. 